\title{
Calculation, qualculation, calqulation: em um mercado de alimentação local
}

Calculation, qualculation, calqulation: in a food local market

Solange Riveli de Oliveira (solangeriveli.oliveira@ufjf.edu.br)

Mestre em Administração, Universidade Federal de Lavras, Lavras - Minas Gerais

Daniel Carvalho de Rezende (danielderezende@dae.vfla.br)

Doutor em Ciências Sociais em Desenvolvimento, Agricultura e Sociedade, Universidade Federal Rural do Rio de Janeiro, Seropédica - Rio de Janeiro

\section{RESUMO}

As feiras são usadas para promover o mercado de alimentação local. Este estudo foi desenvolvido na "Feira Livre do Produtor", em São João Del-Rei, Minas Gerais, sob inspiração da teoria ator-rede (TAR) e o consequente desdobramento conceitual, agenciamento. O objetivo foi descrever o cálculo de valor realizado em relação aos alimentos. Foram feitas entrevistas, análise documental, observação e análise de conteúdo do material coletado. A pesquisa demonstrou uma variedade de cálculos, quantitativosqualitativos-coletivos (Cochoy, 2010) que agem na atribuição de preço. Os resultados revelaram que é possível estudar preço sem, no entanto, demonstrar variáveis numéricas, que os custos dos produtos são pouco considerados pelos feirantes, que a comparação de preços entre feirantes, preço no atacado e no varejo agem fortemente sobre o cálculo. Portanto, os diversos agentes e agências calculativas se confrontam e é complexo delimitar os limites de cada um.

Palavras-chave: mercado de alimentação local, feira livre, calculation.

\section{ABSTRACT}

Farmer markets are used to promote local food that is emerging as a phenomenon (of investigation). This research was developed in a farmer market in São João del-Rei, Brazil, inspired by the actor network theory (ANT) and its consequent conceptual development, agency. The aim was to describe how calculation is made for foods. The material collected consists of Interviews, documental analysis, observation and content analysis. The research demonstrated a variety of calculation, calculation-qualculationcalqualation, (Cochoy, 2010) which act on the pricing. Findings showed that is possible studying price without, however, demonstrating numeric variables, 
that product costs are barely considered by farmers, that price comparison between farmers, wholesale price and retail price are strongly used on calculation. Therefore, there are various conflicting agents and calculative agencies and it is complex to delimitate the boundary of each one.

Keywords: food local market, farmer market, calculation.

\section{INTRODUÇÃO}

O movimento de alimentação local está presente na Europa e Estados Unidos e inspira pesquisas nos mais diversos campos: em relação aos dispositivos de mercado, configurações de mercado, motivações dos consumidores e estratégias utilizadas pelos produtores (Thilmany, Bond \& Bond, 2008).

No Brasil temos grande expressão do mercado de alimentação local nas feiras livres, visto que as iniciativas relacionadas à promoção de atividades locais as assinalam como um caminho a ser seguido. Sendo uma das mais antigas formas de varejo (Ângulo, 2003), elas fazem parte da tradição mineira (Ribeiro, Castro, Silvestre, Calixto, Araújo, Galizoni \& Ayres, 2005).

Com o intuito de promover o comércio de produtores rurais do Campo das Vertentes, a prefeitura municipal cria, em 201 1, a "Feira Livre do Produtor". O mercado de alimentação local do município de São João Del-Rei é objeto desta pesquisa, que irá abordar aspectos característicos desse mercado e a influência de diversos agentes na sua constituição. Para tanto, o mercado na feira foi estudado sob a inspiração da Teoria Ator-Rede (TAR) e o consequente desdobramento conceitual, O agenciamento. Sobre os pressupostos consideramos, especialmente, os aspectos que mais influenciaram os estudos mercadológicos. O primeiro deles é a simetria entre o material e o humano, visto que a realidade (um mercado) é formada por coletivos híbridos. Esses coletivos híbridos se relacionam ao segundo aspecto, de igual importância: a ação, já que esses coletivos são resultados e estimulam outras ações 
responsáveis pelo terceiro elemento, também de igual importância em relação aos primeiros, que é a constante reconfiguração da realidade.

Esse trabalho tem como objetivo descrever o cálculo realizado pelas pessoas em relação aos alimentos de uma feira livre do produtor. Considerando a igualdade de circunstância entre a materialidade e ação humana, foi trabalhado neste artigo, o conceito de cálculo de valor (calculation).

Este estudo explora os diversos elementos considerados pelos agentes calculistas da "Feira Livre do Produtor". Os resultados discutem a complexidade de uma realidade heterogênea composta por cálculos não efetivamente quantitativos, mas também qualitativos. Essa pesquisa permitiu identificar os cálculos feitos e que afetam a configuração do mercado de alimentos locais. Para tanto foi realizada uma pesquisa qualitativa pautada análise documental, na observação, em entrevistas semiestruturadas com os agentes envolvidos. A análise dos dados foi balizada nos preceitos da análise de conteúdo.

\section{REFERENCIAL TEÓRICO}

A pesquisa foi fundamentada em um referencial que permitisse conceber a realidade e o mercado como algo que constantemente se reconfigura, pois está sob a influência de diversas ações. Múltiplos cálculos fazem parte dessa realidade e influenciam os valores atribuídos aos produtos, que no caso desta pesquisa, que produtos provenientes de um mercado que contempla a alimentação local. Nesse sentido, o seguinte referencial teórico irá abordar esses assuntos em duas categorias e duas subcategorias.

\section{Conceituando o mercado com base na TAR}

Não é fácil estabelecer os limites físicos de um mercado (Callon, 1998; Callon \& Muniesa, 2005; Azimont \& Araujo, 2007) já que a moldação de mercado implica em um mútuo desenvolvimento de relações, troca de 
objetos e serviços. A forma que o mercado assume é resultado de múltiplos esforços para tentar moldá-lo (Geiger \& Finch, 2009).

A TAR considera aspectos como a materialidade, os não humanos de modo a compreender a ação humana e a constituição de coletivos. Essa característica da teoria foi estendida e vem fundamentando os recentes estudos sobre mercado (Callon, 1997, 2008; Finch \& Acha, 2008).

Callon destaca que a agência é um desdobramento conceitual da TAR (apud Mattedi, Grisotti, Spiess \& Bennertz, 2009). O conceito agenciamento não deixa nada fora, isso inclui crença, cultura, dispositivo e desempenho (McFall, 2009). Não é possível entender os agenciamentos se a noção de agência ficar restrita somente aos humanos, visto que os acoplados heterogêneos também produzem efeitos (Oliveira \& Rosana, 2005). Nesse sentido, de acordo com Berndt e Boeckler (2010), Muniesa, Millo e Callon (2007), não devemos considerar a distribuição de agência como um encontro entre pessoas e mecanismos, mas considerá-la como um resultado de diversos agenciamentos.

Diante disso, o mercado não envolve tão somente ações preestabelecidas, sendo resultado de esforços práticos de organização (Araújo, Finch \& Kjellberg, 2010; Kjellberg \& Helgesson, 2007). Ao contrário, diariamente, múltiplos frames (enquadramentos) são tidos como referência e não se limitam a racionalidade instrumental e econômica (Araújo, 2007). Por assim dizer, o mercado está sempre sendo construído ao invés de estar feito (Araújo, Finch \& Kjellberg, 2010), pois múltiplas configurações de trocas entre grupo de pessoas e as configurações são frequentemente redefinidas (Araújo, 2007; Azimont \& Araújo, 2007).

O mercado pode ser descrito, no mínimo parcialmente, como um dispositivo coletivo para avaliação das mercadorias. Isso só é possível somente se as mercadorias puderem ser calculadas pelas agências calculativas cujos encontros são organizados e estabilizados a um maior ou menor grau. Essa 
abordagem enfatiza as diversas formas no qual o mercado pode ser organizado. As agências calculativas são tão numerosas e diversas quanto às ferramentas que elas usam e os dispositivos híbridos para as quais aquelas ferramentas pertencem (Callon \& Muniesa, 2005).

\section{Cálculo}

A proliferação dos números depende e afeta a vida social. É preciso considerar que os números estão envolvidos em uma ordem intermediada pela situação social e eles possuem uma vulnerabilidade que contribui para a perda da realidade, visto que as situações sociais em que os números são usados se relacionam com as transformações imediatas (Vollmer, 2007).

Nesse sentido, a TAR oferece suporte para compreender os aspectos da contabilidade ao teorizar sobre como os vários aspectos contábeis interagem e se reconfiguram (Skaerbaek, 2009). Nessa perspectiva, é possível compreender como os cálculos obtêm poder no mundo real de decisão, uma vez que eles envolvem a promoção ativa de atores e o enquadramento que se incorporam nas regras do jogo (Åkerman \& Peltola, 2012).

As ciências sociais assumiram que o entendimento sobre racional e irracional era mutuamente excludentes. Mas, na verdade, a avaliação racional é embaraçosamente ligada com emoções (Callon \& Law, 2003) e isso contribui para as conflitantes racionalidades econômicas calculativas (Åkerman \& Peltola, 2012). Portanto, o caráter calculativo de mercado envolve agentes em relações que multiplicam sua reflexão e ação, já que as agências calculativas se confrontam (Callon \& Muniesa, 2005).

Azimon e Araujo (2010) apontam que Callon traz uma posição radicalmente diferente da economia, que possui um instrumento quantitativo. Ao invés de assumir que os agentes são instrumentos para serem calculados, Callon propõe transformar as agências calculativas em objetos de investigação e realização do cálculo. 
Embora alguns críticos considerem, segundo Åkerman e Peltola (2012), que o desenvolvimento de novas racionalidades calculativas não ajuda, mas obscurece a decisão, Callon e Muniesa (2005) destacam que o intuito é tornar o caráter calculativo do mercado teoricamente menos controverso e mais realista. Para isso propuseram a revisão do termo calculation (cálculo de valor). Os cálculos econômicos não são apenas uma questão mecânica humana, eles estão distribuídos entre os atores humanos e os dispositivos materiais (Azimont \& Araujo, 2010).

Atualmente, as interpretações de Cochoy acerca do conceito de cálculo de valor merecem destaque, especialmente pelo caráter didático da abordagem.

Cochoy (2008) propõe uma tríade calculation-qualculation-calqulation (cálculo quantitativo-cálculo qualitativo-cálculo coletivo) que ajuda a coordenar os aspectos quantitativos da escolha do consumidor (cálculo quantitativo) com as propriedades mundanas e materiais envolvidos (cálculo qualitativo) e o ambiente social (cálculo coletivo).

Segundo Cochoy (2008), o cálculo quantitativo é um processo de escolha em que o indivíduo pondera e avalia os aspectos quantitativos. Na falta de pontos explicitamente quantitativos os envolvidos realizam uma avaliação delicada da melhor opção possível com base em parâmetros não quantitativos. A noção de cálculo qualitativo de Cochoy realça que o cálculo envolve componentes qualitativos e quantitativos, métricas como também julgamentos. Definir as qualidades das coisas é parte integrante da calculabilidade (Azimont \& Araujo, 2010). O cálculo qualitativo está relacionado a situações em que os consumidores precisam escolher entre objetos colocados no mesmo quadro espacial e temporal (Callon \& Muniesa, 2005).

O terceiro elemento da tríade é cálculo coletivo. As escolhas são sempre construídas e debatidas coletivamente através da vibração invisível 
de pessoas e mercadorias que fazem parte do mercado. A essa influência da coletividade na escolha do consumidor, o autor da o nome de "calqulation" (oriundo do verbo francês "calquer", que significa "seguir um modelo"). Ocorre quando um indivíduo compara suas escolhas com as de outras pessoas ou baseia-se nas normas sociais e comportamentos para avaliar sua própria escolha (Cochoy, 2008).

Portanto, vários são os elementos considerados no processo de cálculo. Dentre os elementos quantitativos, o preço possui papel de destaque. Para Caliskan (2007), os preços são produzidos pelos atores que participam do processo de compra e venda. Sendo o cálculo expresso na forma de preço outras pessoas passam a avaliar o produto (Callon \& Muniesa, 2005).

Deste modo, o mercado é um dispositivo calculativo que favorece múltiplos cálculos e a avaliação de produtos (Cochoy, 2008). Os mercados são dispositivos coletivos que possibilitam que os compromissos sejam alcançados não apenas para que os produtos sejam produzidos e distribuídos, mas para possibilitar a atribuição de valor (Callon \& Muniesa, 2005) e, dos números que torna possível a circulação desses produtos na sociedade (Azimont \& Araujo, 2010).

Cochoy (2010) realizou uma pesquisa que procurou analisar a progressão que as mercearias tiveram ao longo do tempo, especificamente durante os períodos de 1929 e 1959. O autor investigou como novos equipamentos ou as disposições das mercearias direcionavam o consumo e - modo como os consumidores realizavam suas avaliações acerca dos produtos. Ao longo das décadas, as mercearias obtiveram os layouts alterados. Fazendo uma alusão ao mundo rural, Cochoy (2010) ressalta duas estratégias: fencing e branding. Fencing estaria relacionado às cercas de arames farpados que limitam a circulação do gado na propriedade. De modo análogo, os produtos das mercearias ficavam cercados pelos balcões e as compras eram realizadas pela intermediação direta com o atendente. Já no modo Branding, que se relaciona às marcas (branding iron) que o gado 
recebe, promove os direitos de propriedade para além de uma determinada área restrita. Nesse caso, os produtos recebem um código de barra, sem a necessidade de ficarem "cercados". As estratégias de Branding promovem o autosserviço e participação do consumidor, pois os produtos ficam expostos em prateleiras e cada um possui sua marca própria que é visível a todos. Dessa forma, diversas são as influências que interferem nas avaliações e escolhas (Cochoy, 2010).

Callon e Muniesa (2005) afirmam que o leque é amplo. Há varias formas de calcular valores. Os autores abordam que mais e mais atores estão envolvidos na intervenção e funcionamento do mercado e, assim como Åkerman e Peltola (2012), precisamos considerar que as relações ocorrem exatamente pelo cálculo envolver diversas agências calculativas.

\section{Mercado de alimentação local e feira dos produtores}

Atualmente está havendo um movimento rumo à (re)localização que tem se tornado um lema de contraponto a globalização. A evidência do fenômeno de alimentação local ocorre, em especial, na Europa e Estados Unidos (Kirwan \& Maye, 2012; Mount, 2011; Thilmany, Bond \& Bond, 2008; Weatherell, Tregear \& Allinson, 2003).

Uma grande evidência do reconhecimento desse fenômeno, conforme Thilmany, Bond e Bond (2008) foi a inclusão do conceito de locavores no novo dicionário de Oxford em 2007. Locavores são as pessoas cuja dieta consiste somente ou principalmente de alimentação produzida ou crescida localmente.

Hinrichs (2003) destaca que a alimentação local emergiu como uma tentativa das pessoas se oporem ao sistema e à tendência de concentração econômica, degradação ambiental e a favor do fortalecimento dos agentes sociais em localizações rurais.

Diante disso, a emergência desta configuração traz potenciais benefícios, como a redução dos quilômetros percorridos e benfeitorias sobre 
a renda da região (Kirwan \& Maye, 2012; Morris \& Buller, 2003), visto que parte do dinheiro gasto com alimentação local permanece naquela localidade. Além disso, os consumidores têm melhor informação sobre a origem dos produtos e modo de produção (Weatherell, Tregear \& Allinson, 2003).

Contudo, o local nem sempre estará associado a causas sociais ou ambientais. Kneafsey (2010) nos alerta para algumas armadilhas acerca de local. Associar um produto à questão local não deve ser encarado como algo necessariamente desejável e que inclua qualidades ecológicas, sustentáveis ou de justiça social.

Apesar da forte evidência apontada pela literatura do fenômeno de alimentação local, não há um conceito definido do que seria o "local" (Morris \& Buller, 2003; Martinez, Hand, Da Pra, Pollack, Ralston, Smith, Vogel, Clark, Lohr, Low \& Newman, 2010; Zepeda \& Leviten-Reid, 2004).

Kneafsey (2010) não define esse mercado como aquele envolvido em uma pequena cadeia e conduzido apenas por produtores. Morris e Buller (2003) esclarecem a existência de duas perspectivas. A primeira está relacionada a um "sistema fechado", no qual a alimentação é produzida, processada e distribuída dentro de um limite geográfico, definido como local. A outra perspectiva entende a localidade como um valor a ser adicionado aos produtos que são certificados como provenientes de determinada área ou região, mas não são comercializados naquele limite geográfico.

Destacamos que, neste trabalho, o local está baseado no produtor que vende (diretamente) para consumidores que estão localizados no mercado de fazendeiros/produtores da região, ou seja, região próxima à cidade (Kneafsey, 2010). Assim, alimentação local será entendida como "alimento produzido, processado, e distribuído em um espaço geográfico particular e que consumidores associam com sua própria comunidade" (Martinez et al., 2010). 
As feiras tendem a ser iniciativas de âmbito local (Ribeiro et al., 2005), especialmente em se tratando de municípios de pequeno e médio portes (Ângulo, 2003).

No Brasil, as feiras livres são uma das mais antigas formas de varejo e fazem parte da tradição mineira (Ângulo, 2003; Ribeiro et al., 2005). Elas garantem a obtenção de uma renda familiar e afigura-se como um espaço de socialização (Ângulo, 2003).

Tornando-se um dos espaços preferenciais para os produtores, esse mercado seria um meio para consolidação do negócio. A feira é fundamental na renda do agricultor familiar da região. Em muitos casos, se apresenta como a única alternativa de obtenção de renda proveniente da propriedade. Nesse sentido, pode significar uma alternativa viável para as pessoas que não conseguem emprego ou possuem condição precária no mercado de trabalho (Ângulo, 2003; Sá, 2010).

Dessa forma, a feira proporciona aos agricultores um espaço para comercialização que garante a inserção no mercado urbano. Contudo, vale destacar que podemos encontrar muitos feirantes que vieram do campo para serem projetados na cidade. Ainda que a feira esteja relacionada a formas antigas de comércio, tal atividade apresenta uma realidade dual, pois ao mesmo tempo em que está pautada em aspectos tradicionais de determinada região também contribui para a dinâmica capitalista moderna (Sá, 2010).

O papel das feiras vai além da simples comercialização. As feiras são um evento social, caracterizadas por um ambiente de lazer e não apenas de consumo (Silvestre, Ribeiro \& Freitas, 2011). Ainda, elas também são tidas como um espaço de expressão cultural ao revelar características tradicionais de determinada região (Sá, 2010; Pimentel, 2005) e se revela como espaço para relações de amizade, confiança e intimidade. 
Por fim, as feiras contribuem para a dinamização das economias locais e são como espelho de uma sociedade que é conhecida e avaliada pela população e pelas entidades locais (Ângulo, 2003).

\section{METODOLOGIA}

A estratégia metodológica utilizada para viabilizar os objetivos foi um estudo aprofundado e de natureza qualitativa realizado na Feira Livre do Produtor no município de São João Del-Rei por aquela se tratar de um mercado de alimentação local.

A TAR foi a base do argumento científico em relação à visão de mundo e nos orientou quanto à direção da discussão teórica (Tonelli, 2011 ).

A pesquisa foi desenvolvida a partir de múltiplas coletas de dados. Foi utilizada a observação não participante na qual o pesquisador se insere e observa o indivíduo, mas o não se faz passar por um dos envolvidos. Foram realizadas entrevistas semiestruturadas, baseadas em um roteiro de pesquisa. Essa forma de entrevista permite que os entrevistados se expressem melhor em uma situação de entrevista com planejamento relativamente aberto (Flick, 2004).

Foram realizadas entrevistas com consumidores, feirantes e agentes da prefeitura. Em todas as entrevistas o objetivo da pesquisa foi esclarecido.

Foram entrevistados 19 agentes, sendo 6 consumidores, 10 feirantes, 2 agentes da prefeitura e 1 fornecedor. As entrevistas foram transcritas e analisadas por meio da Análise de Conteúdo. Embora tenha sido balizada sob uma abordagem quantitativa, aquela pode envolver abordagens qualitativas (Vergara, 2006). Segundo Bardin (1977) a análise qualitativa não depende da frequência suficientemente elevada e focaliza as peculiaridades dos elementos, dando ênfase ao que é significativo e relevante (Vergara, 2006).

Para realização deste trabalho, escolhemos a grade aberta, que procura identificar as categorias de análise, conforme foram surgindo até chegar às categorias finais (Vergara, 2006). 
Como o trabalho não se limitou apenas a entrevistas, as categorias foram criadas considerando todo o material coletado. Ou seja, uma mesma categoria envolve relatos de diferentes agentes e são complementadas por informações do regulamento, do informativo e das observações.

\section{RESULTADOS E DISCUSSÃO}

A feira livre do produtor em São João Del-Rei ocorre desde o início do ano de 2011 e funciona aos domingos, com o intuito de elevar a autoestima e fortalecer as ações dos produtores rurais do Campo das Vertentes.

A configuração do mercado de alimentação local estabelecido na feira livre do produtor demonstrou que esta é formada não apenas por aspectos de cunho econômico. Para o feirante, a feira ajuda a promover o seu produto, divulgar a produção de pães, biscoitos e hortaliças. Ainda, ela se configura como um espaço propício para promover conversas e conhecer pessoas. Com isso, a feira também passa a se tornar um entretenimento para o consumidor. Mesmo não realizando compras em determinado dia, alguns frequentadores vão à feira para passear, outros levam a família para fazer compras. Além disso, os consumidores buscam na feira produtos frescos, colhidos no dia ou há poucos dias. Alguns consumidores dizem reconhecer essas qualidades no produto, outros obtêm informações por meio de pessoas conhecidas, sejam elas consumidores ou feirantes. Contudo, notamos que poucas informações são disponibilizadas aos consumidores acerca dos produtos e produtores. Algumas poucas barracas trazem faixas com nome da associação a qual pertencem os feirantes. Vale destacar que os consumidores percebem a feira também é um local onde podem ser encontrados diversos produtos que não são dos produtores.

Alguns consumidores têm dificuldade em achar as barracas em que compraram os produtos. Dependendo da semana, os feirantes mudam de lugar devido à ausência de algum colega comerciante ou outra 
eventualidade. Apenas uma barraca possui numeração ou identificação visível. Em meio à multidão, elas dificilmente são diferenciadas.

Além disso, os preços não são expostos para os consumidores, ou seja, não existem dispositivos como tabela de preços, etiquetas ou placas.

A feira é organizada em 3 setores: artesanato (setor A - 10 barracas), hortifrutigranjeiros, pescado, conservas, produtos derivados do leite e da carne (setor B - 30 a 40 barracas), e praça de alimentação (setor C - 10 a 15 barracas). O presente artigo teve como foco estudar o cálculo de valor realizado no setor $\mathrm{B}$.

Uma dificuldade encontrada para elaboração deste artigo deve-se à diversidade dos produtos. Ou seja, não foi pesquisado apenas o cálculo acerca de um produto específico da feira. Mesmo o foco da pesquisa sendo o setor B, nesse setor há uma grande diversidade de produtos alimentícios que são comercializados. Dessa forma, buscaremos abordar aqui o processo de cálculo comum aos produtos.

\section{Quantidade ofertada}

Os preços dos produtos são formados tendo como base a quantidade de produto ofertado. Para os feirantes o preço geralmente varia pela oferta no mercado. Contudo, verificamos que o preço do tomate, citado pelos entrevistados, sofreu oscilações entre uma semana e outra durante o ano de 2012, não apenas no mercado local (tendo por objeto a feira), mas em toda a cidade. Isso pode ter ocorrido devido às respostas de vendas da semana e por ser um produto não perecível. Sabemos que, se o preço está alto a venda diminui, e consequentemente, nas próximas semanas o preço abaixa. Contudo, os produtos não passam apenas por essa forma de cálculo. Callon e Muniesa (2005) destacam que é um risco retornar à visão formal e abstrata ao considerar um mercado governado por leis impessoais, como é o caso da lei da demanda. Isso consistiria em assumir que os agentes econômicos possuem preferências e competências calculistas reduzidas. Portanto, outros modos calculistas são realizados. 


\section{Preços dos produtos repassados para Central de abastecimento e} atacado

O preço que os feirantes estabelecem na feira é influenciado pelo preço que eles repassam para a Central de Abastecimento, CEASA, em Belo Horizonte. A capital mineira fica a uma distância aproximada de 180 quilômetros de São João Del-Rei. O preço no atacado causa as variações nos preços do varejo, fazendo-se notar uma forte participação do atacado na formação de preços (Adami \& Miranda, 2011). De modo análogo ao que ocorre no mercado de arroz, os preços no mercado dominante influenciam os preços no mercado seguidor. A transmissão de preços dá-se do produtor para o varejo e do atacado para o varejo (Adami \& Miranda, 2011). Dessa forma, os grandes compradores atuam de modo voluntário ou não, na conjuntura de preços (Farina \& Nunes, 2002).

Preços dos produtos comercializados em supermercados, mercearias ou outros estabelecimentos comerciais

Embora alguns feirantes digam não comparar os seus preços com o dos supermercados e outros varejistas, uma análise mais aprofundada das entrevistas revela que os feirantes consideram os preços dos produtos de outros estabelecimentos comerciais. Além dos feirantes, os consumidores também consideram o preço dos supermercados. Mesmo não realizando pesquisas nos mercados periódica e formalmente, conforme previsto no regulamento, os preços dos supermercados e mercearias agem sobre os preços estabelecidos na feira. A conversa com feirantes nos permitiu aprender que eles sabem dos preços por trabalhar em supermercados, ou por serem proprietários de mercearias, padarias. Muitos feirantes comparam o preço dos produtos com os preços estabelecidos em seus próprios estabelecimentos comerciais.

Por outro lado, os preços dos supermercados, mercearias, também podem agir no sentido de elevar o preço na feira. Ao comparar o preço, o 
feirante o faz considerando a cidade onde produz e comercializa. A viagem, transporte, dependendo da localidade, tende a conduzir a uma elevação dos preços. Associadas aos gastos de transporte estão as perdas provenientes da viagem. Contudo, de um modo geral, outros feirantes não consideram, ou não deixaram transparecer nas entrevistas, os gastos com transporte para o cálculo do preço. Alguns feirantes vêm de ônibus, outros possuem o próprio automóvel e não associam isso ao custo de produção.

\section{Feirantes possuem outros pontos de venda}

Cada feirante possui um perfil. Muitos feirantes trabalham na feira que se configura como uma oportunidade de complementação da renda. Trabalhar em outros estabelecimentos, ter o próprio negócio e vender para outros clientes são ações que abrem uma nova oportunidade de cálculo na feira. Os preços dos produtos são alterados de acordo com a avaliação das outras opções de fornecimento dos feirantes. Por alguns feirantes participarem de associações, eles fornecem para escolas ou possuem outros canais de vendas como supermercados, mercearias, vizinhança, CEASA e outros. Tendo outra fonte de escoamento das mercadorias, muitas vezes, eles preferem não abaixar o preço na feira. Contudo, isso vai depender se os produtos vão permanecer em bom estado para vendas posteriores, como também do recebimento do valor da mercadoria, afinal, conforme Silvestre, Calixto e Ribeiro (2005), vender na feira é uma oportunidade que os produtores têm de receber à vista e perceberem os retornos da produção de modo mais imediato.

\section{Produtos que não são dos feirantes}

De acordo com o regulamento, é "[...] expressamente proibida a comercialização de produtos por intermediários [...]" (Artigo 29%). Contudo, ocorrem transbordamentos. Nem todos os feirantes são produtores. Muitos feirantes comercializam produtos que não são produzidos por eles. Os produtos são de vizinhos, de outros feirantes (que, inclusive não produzem no Estado de Minas Gerais) ou provenientes da CEASA e supermercados. Tudo 
isso influencia o cálculo na feira, pois as ações sobre negociação são afetadas. Então, comercializar produtos que não são produzidos por eles pode dificultar a negociação, já que esses feirantes têm um preço mínimo já preestabelecido. Dessa forma, o produtor possui maior liberdade para estabelecer o preço e assim influenciar o cálculo do consumidor por meio da negociação. Comprar de outro produtor para vender na feira é uma prática que está se tornando comum. Vale destacar que, ao revender produtos, o cálculo dos preços se restringe primeira e especialmente ao preço no qual o produto foi comprado.

\section{Negociação de final de expediente}

Geralmente, no final de expediente das feiras, os produtos tendem a baratear. Ribeiro et al. (2005) destacam que nos horários iniciais de funcionamento estão à venda produtos com preços mais elevados. A situação tende a se inverter com o passar das horas e nota-se uma queda nos preços.

Conforme abordado, o fato de os feirantes possuírem outros pontos de vendas influencia também a formação dos preços ao final do expediente, já que eles têm a opção de vender a mercadoria posteriormente. Assim, alguns feirantes optam por não diminuir os preços.

Por outro lado, alterar o preço nessa fase se justifica devido ao feirante, principalmente aquele que oferta produtos perecíveis, poder optar por desfazer-se mais rapidamente dos produtos que ainda não foram vendidos. Também eles não gostam de voltar para sua propriedade com a mercadoria que é considerada "sobra" e não vai ser consumida. Também ocorre que, no fim da feira, os produtos não possuem mais as características necessárias para a manutenção dos preços estipulados para o período inicial da feira (Silvestre, Calixto \& Ribeiro, 2005), por estarem murchos, por exemplo.

\section{Negociação com clientes}


A negociação com clientes é algo recorrente na feira. Por vezes, a barganha não ocorre somente por oferecer ou solicitar um produto a um preço menor, mas por oferecer ou pedir produtos a mais.

A negociação ocorre tendo outros aspectos que fazem o feirante agir: a perecibilidade, quantidade do produto, e o fato de estar ou não no fim da feira.

Não frequentemente, é possível ver os feirantes, especialmente da parte de hortaliças, darem outros produtos aos clientes. Produtores e consumidores constroem um mercado no qual a negociação entre eles está sendo realizada de modo a estabilizar esse mesmo mercado. Essa configuração é muito diferente das encontradas em supermercados, por exemplo, nos quais os produtos são simplesmente dispostos em prateleiras (Cochoy, 2010). No caso da feira, além dos produtos estarem expostos, os agentes tem maior interação.

Um fato interessante é a postura de alguns consumidores em relação à tentativa de barganha. Dentre as implicações apresentadas percebemos que essas consumidoras acreditam que os produtos já possuem preço bom, e assim não agem para diminuírem ainda mais o valor. É interessante esse aspecto pelo fato de algumas pesquisas apontarem o consumo mais consciente em mercado local. O mercado de alimentação local pode ajudar a criar um ambiente favorável aos produtores (Morris \& Buller, 2003), visto que consumidores expressam um comportamento de apoio político e ético em relação ao consumo (Dubuisson-Quellier, 2010).

\section{Comparação entre feirantes}

Os feirantes realizam diversos cálculos e também agem sobre os cálculos de outros feirantes para assim expressarem em forma de preço. Os feirantes declaram atribuir preços aos produtos tendo como base os preços de outros feirantes. Feirantes que vendem produtos orgânicos, mesmo acreditando que os produtos sejam diferenciados, acompanham o preço de outros feirantes. A preocupação com os preços vizinhos é latente. 
Percebemos um espaço de concorrência, mas também de cooperação, "conversamos para manter mais ou menos o preço" ou então "para nenhum prejudicar o outro". Dessa forma, a feira é uma oportunidade para que os produtores aprendam a trabalhar e se organizar coletivamente. Mesmo não sabendo do custo de produção, os feirantes costumam acompanhar os preços uns dos outros.

Mesmo os feirantes procurando realizar os cálculos com base nos produtos de outros feirantes, o final da feira influencia no cálculo já realizado. E assim, torna-se presente a reiterada comparação entre os preços estabelecidos pelos feirantes. Um feirante reavalia o próprio cálculo tendo como base o preço dos outros feirantes. É comum presenciar um feirante conversando sobre preço com o vizinho ou andando pela feira e perguntando o preço de determinado produto. Essa configuração se complementa pela postura dos consumidores. Mesmo considerando o preço estabelecido na feira mais baixo que nos supermercados, os consumidores realizam suas avaliações comparando o preço na feira. Mais que isso, os próprios consumidores agem no sentido de informar aos feirantes sobre os preços dos outros feirantes e, para se manterem competitivos, os feirantes reagem dessa forma.

\section{Custo dos produtos}

Poucos feirantes mencionaram a contabilização do custo de produção. Outros nem mesmo realizam qualquer cálculo.

Os feirantes, que demonstraram fazer os cálculos utilizando dispositivos como as planilhas para contabilizar os custos, são aqueles que possuem estabelecimentos comerciais ou grandes produtores. Por ter uma escala de produção maior, produzir em outros estados e possuir funcionários contribui para que o feirante assuma esse tipo de cálculo, prevendo perdas e ganhos que se dão em maiores proporções. 
O preço de custo não é considerado por boa parte dos feirantes. Eles não calculam (nesse caso há predominância de cálculo quantitativo) o quanto gastam. Poucos são os feirantes que atribuem determinado preço tendo como base de cálculo custos de mãos de obra, da terra e outros.

Devemos considerar também que para alguns feirantes o preço de custo é o preço pelo qual compraram os produtos para revender Dessa forma, eles conseguem ter uma visão mais clara sobre o cálculo com predominância quantitativa e, assim, mensurar o preço.

É evidente que o cálculo é composto por diversos elementos que não são contabilizados em planilhas numéricas. Notamos que o caráter calculativo de mercado envolve compreender que os agentes envolvidos nas relações refazem sua reflexão e ação, já que as agências calculativas se confrontam (Callon \& Muniesa, 2005). A figura 1 abaixo procura ilustrar a composição do cálculo. Não se trata de um modelo, mas de uma descrição sobre como o cálculo é realizado, atribuindo preço ao produto.

Figura 1: Descrição ilustrativa do cálculo e expressão na forma de preço 


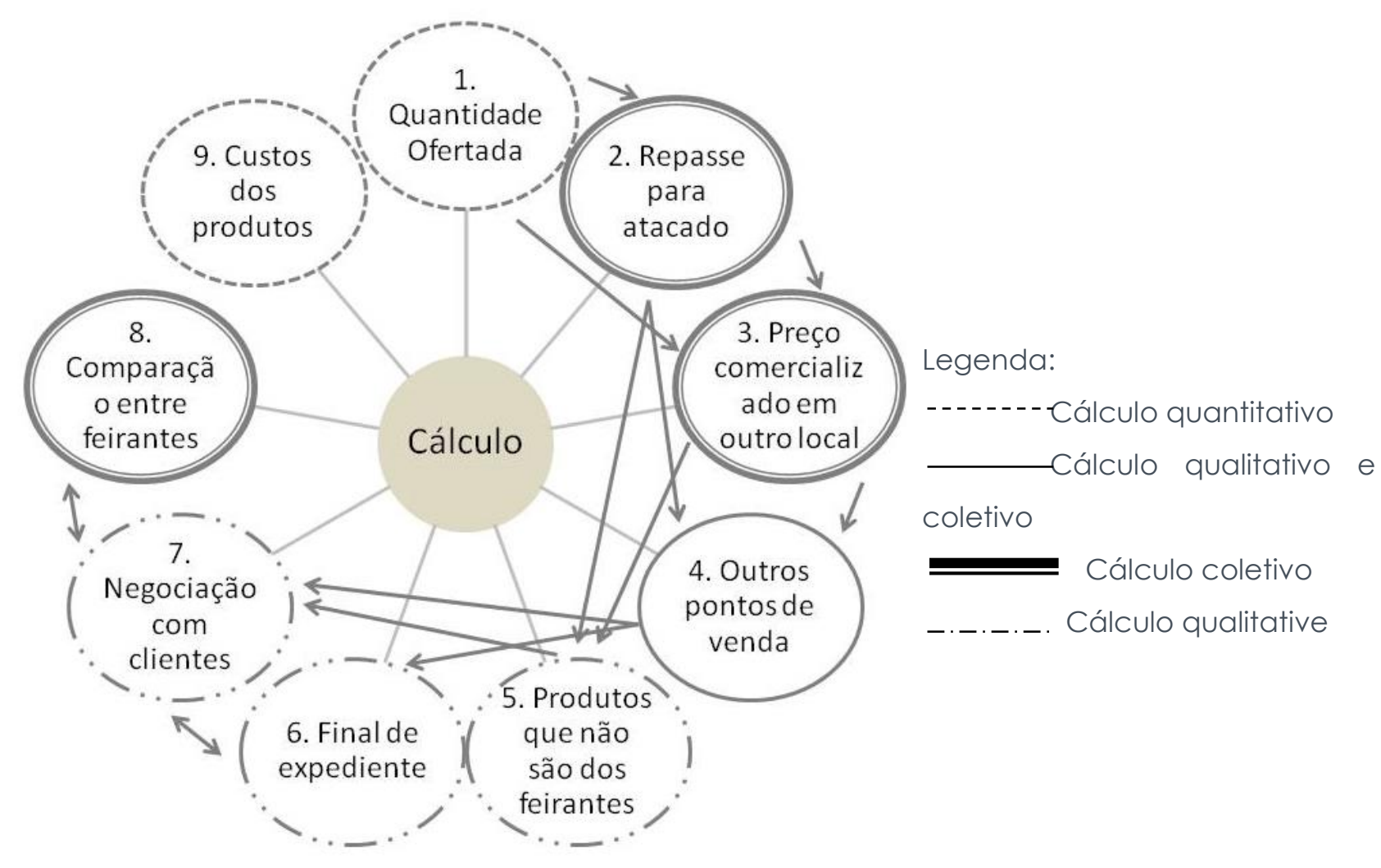

Fonte: Elaborado pelos autores

Cochoy (2008) apresenta os elementos da tríade cálculo quantitativo, cálculo qualitativo, cálculo coletivo. Neste estudo podemos identificar as categorias e classifica-las de acordo com a tríade, conforme ilustrado na figura 1. O processo de escolha pode ser feito através da avaliação de aspectos predominantemente quantitativos, cálculos predominantemente qualitativos ou pela coletividade e a observância de um modelo a ser seguido. Nesse sentido, Cochoy (2008) denomina o processo de calqulation ou cálculo coletivo.

Ainda, é possível perceber como os cálculos influenciam mutuamente.

O estudo de Cochoy (2010) nos permite sugerir, no contexto da feira, uma inversão do que ocorreu nas mercearias desde 1930. Acreditamos que a configuração da feira está mais relacionada às estratégias iniciais de fencing. A configuração do mercado da feira apresenta aspectos tradicionais do 
comércio. Nesse contexto, temos que os produtos estão dispostos em bancas e, por limitações de espaços ficam em caixotes. Além disso, os feirantes estão o tempo todo presentes e intermediando essas compras. Tudo isso influencia na forma como os cálculos são realizados, especialmente pelos consumidores, pois a feira se configura como espaço calculativo.

\section{CONSIDERAÇÕES FINAIS}

A pesquisa demonstrou que o processo de cálculo abarca diversas ações dos agentes no mercado. Essas ações ora são pensadas ora não, sendo que, a todo instante, o conjunto de ações se influenciam mutuamente. É complexo delimitar a abrangência e prevalência de uma ou outra e também não é simples determinar se a configuração é causa ou consequência do processo de cálculo de valor.

Nesse sentido, a perspectiva proposta por Cochoy nos permitiu identificar as diferentes formas de cálculo. Concluímos que é possível falar de preço sem, no entanto, demonstrar variáveis numéricas. Um fato curioso é que os custos dos produtos não são considerados por boa parte dos feirantes, especialmente pelos pequenos produtores rurais. Planilhas de cálculos e outras técnicas de contabilidade estão raramente presentes no conjunto dos dispositivos calculativos.

Temos que a comparação de preços entre os feirantes age fortemente sobre o cálculo, especialmente durante a ocorrência da feira. Destacamos que o preço naquele espaço de mercado de alimentação local, como também o preço no atacado e de supermercados, influencia substancialmente os feirantes a agirem no estabelecimento dos preços. Portanto, os diversos agentes e agências calculativas se confrontam em meio à coletividade.

Em relação à alimentação local, notamos que mesmo que alguns consumidores saibam da existência de produtos que não são produzidos pelos feirantes, há pouca informação disponibilizada sobre o produto e produtor, temos que o consumidor não identifica claramente quais produtos são locais 
ou são dos produtores. Alguns consumidores demonstraram não fazer pechincha, pois consideram que o preço na feira já é baixo e acreditam que todos devem sair ganhando.

Algumas ações tornam-se necessárias. Poderiam ser incentivadas ações de melhoria na feira a partir da organização dos feirantes, divulgação e valorização da feira livre, dos produtos comercializados e dos produtores.

Consideramos que a perspectiva teórica baseada na TAR nos deu suporte para estudar o mercado como resultado das ações dos vários agentes envolvidos. Não se tornou conveniente fazer a distinção entre humanos e não humanos ao longo das análises, visto que essa orientação é especialmente relacionada ao olhar que é dirigido sobre o objeto investigado e sobre os aspectos metodológicos. Além disso, a ideia de agenciamento compreende os agentes como resultados das relações materiais e humanas. Sobretudo, procuramos realizar este estudo baseado não apenas na perspectiva de um ou outro agente, mas na interação entre eles. Acreditamos na validação dessa perspectiva enquanto orientadora de investigações que procuram compreender determinada realidade não como o ponto inicial, mas como o resultado não estático de um longo processo que envolve articulações, intermediações materiais e humanas, e que assumem determinada configuração.

Por fim, este trabalho se limita a discutir de modo generalizado a influência que os agentes exercem sobre o cálculo de valor dos produtos da feira e sobre sua configuração. Além disso, não discutimos a viabilidade em transformar esses elementos em expressões numéricas, já que o cálculo de valor pode ser expresso na forma de preço. Futuras pesquisas podem dedicarse a testar a relação dos elementos que diagnosticamos no processo de cálculo. Outra questão que poderia ser discutida é se os consumidores estariam dispostos a pagar a mais pelos produtos da feira, especialmente pelos locais. Futuros estudos seriam necessários para averiguar tais questões. 


\section{REFERÊNCIAS}

Adami, A. C. O., \& Miranda, S. H. G. (2011). Transmissão de preços e cointegração no mercado brasileiro de arroz. Revista de Economia e Sociologia Rural, 49 (1), 55-80.

Åkerman, M., \& Peltola, T. (2012). How does natural resource accounting become powerful in policymaking? A case study of changing calculative frames in local energy policy in Finland. Ecological Economics, 80, 63-69.

Ângulo, J. L. G. (2003). Mercado local, produção familiar e desenvolvimento: estudo de caso da feira de Turmalina, Vale do Jequitinhonha, MG. Organizações Rurais \& Agroindustriais, 5 (2), 96-109.

Araújo, L., Finch, J., \& Kjellberg, H. (2010). Reconnecting marketing to markets. Oxford: Oxford University.

Araújo, L. (2007). Markets, market-making and marketing. Marketing Theory, 7 (3), 211-226.

Azimont, F., \& Araújo, L. (2007). Category reviews as market-shaping events. Industrial Marketing Management, 36 (7), 849-860.

Azimont, F., \& Araújo, L. (2010). Governing firms, shaping markets. In: L. Araújo, J. Finch \& H. Kjellberg. Reconnecting marketing to markets. Oxford: Oxford University, 78-96.

Bardin, L. (1977). Análise de conteúdo. Lisboa: Edições 70.

Berndt, C., \& Boeckler, M. (2010). Geographies of markets: Materials, morals and monsters in motion. Progress in Human Geography, 35 (4), 559-567.

Caliskan, K. (2007). Price as a market device: cotton trading in Izmir Mercantile Exchange. In: M. Callon, Y. Millo, F. Muniesa. Market devices. London: Blackwell.

Callon, M. (1997). Actor-network theory: the market test (draft). In: J. Law \& J. Hassard. Actor network and after workshop. Keele: Centre for Social Theory and Technology, Keele University, 181-195. 
Callon, M. (1998). 'An essay on framing and overflowing: economic externalities revisited by sociology'. Sociological Review Monograph Series: The laws of the markets, 46 (S1), 244-269.

Callon, M., \& Muniesa, F. (2005). Economic markets as calculative collective devices. Organization Studies, 26 (8), 1229-1250.

Carvalho, F. G., Rezende, E. G., \& Rezende, M. L. (2010). Hábitos de compra dos clientes da feira livre de Alfenas-MG. Organizações Rurais \& Agroindustriais, 12 (1), 131-141.

Cochoy, F. (2008). Calculation, qualculation, calqulation: shopping cart arithmetic, equipped cognition and the clustered consumer. Marketing Theory, 8 (1), 15-44.

Cochoy, F. (2010). Reconnecting marketing to "Market-things": how grocery equipament dorve modern consumption (Progressive Grocer, 19291959). In L. Araújo, J. Finch \& H. Kjellberg. (Ed.). Reconnecting marketing to markets. Oxford: Oxford University.

Cunha, A. M., Simões, R. F., \& Paula, J. A. (2008). História econômica e regionalização: contribuição a um desafio teórico-metodológico. Estudos Econômicos, 38 (3), 493-524.

Dubuisson-Quellier, S. (2010). From consumerism to the empowerment of consumers: the case of consumer oriented movements in france. Sustainability, 2, 1849-1868.

Farina, E. M. M. Q., \& Nunes, R. (2002). A evolução do sistema agroalimentar e a redução de preços para o consumidor: o efeito de atuação dos grandes compradores. São Paulo: PENSA/FIA/ FEA/USP.

Finch, J. H., \& Acha, V. L. (2008). Making and exchanging a second-hand oil field, considered in an industrial marketing setting. Marketing Theory, 8 (1), 45-66. 
Flick, U. (2004). Uma introdução à pesquisa qualitativa. (2 ed.). Porto Alegre: Bookman.

Geiger, S., \& Finch, J. (2009). Industrial sales people as market actors. Industrial Marketing Management, 38, 608-617.

Hinrichs, C. C. (2003). The practice and politics of food system localization. Journal of rural studies, 19 (1), 33-45.

Kjellberg, H., \& Helgesson, C. F. (2007). On the nature of markets and their practices. Marketing Theory, 7 (2), 137-162.

Kneafsey, M. (2010). The region in food--important or irrelevant? Cambridge Journal of Regions, Economy and Society, 3 (2), 177-190.

Martinez, S., Hand, M., Da Pra, M., Pollack, S., Ralston, K., Smith, T., Vogel, S., Clark, S., Lohr, L., Low, S., \& Newman, C. (2010). Local food systems: concepts, impacts, and issues. Washington: USDA.

Mattedi, M. A., Grisotti, M., Spiess, M. R., \& Bennertz, R. (2009). A coperformação das ciências e da sociedade: entrevista com Michel Callon. Política e Sociedade, (14), 386-406.

McFall, L. (2009). Devices and desires: how useful is the 'new' new economic sociology for understanding market attachment? Sociology Compass, 3 (2), 267-282.

Morris, C., \& Buller, H. (2003). The local food sector: a preliminary assessment of its form and impact in Gloucestershire. British Food Journal, 105 (8), 559-566.

Muniesa, F., Millo, Y., \& Callon, M. (2007). An introduction to market devices. Sociological Review, 55, 1-12. Disponível em: <<Goto |SI>://WOS:000249954500001>. Acesso em: 19 set. 2012.

Oliveira, R. M. (2005). Tecnologia e subjetivação: a questão da agência. Psicologia \& Sociedade, 17 (1), 17-28. 
Pimentel, T. D. (2005). De "Woodstock Mineira" a "Camelódromo": percurso semântico da transformação da identidade em uma feira. Encontro da Associação Nacional de Pós-Graduação e Pesquisa em Administração, 29, Brasília. Anais... Brasília: ANPAD.

Ribeiro, E. M., Castro, B. S. de., Silvestre, L. H., Calixto, J. S., Araújo, D. P., Galizoni, F. M., \& Ayres, E. B. (2005). Programa de apoio às feiras e à agricultura familiar no Jequitinhonha mineiro. Agriculturas, 2 (2), 5-9.

Sá, M. G. (2010). Feirantes: quem são? Como administram seus negócios? Encontro da Associação Nacional de Pós-Graduação d Pesquisa em Administração, 34, Rio de Janeiro. Anais... Rio de Janeiro: ANPAD.

Silvestre, I. H. A., Ribeiro, A. E. M., \& Freitas, C. S. (2011). Subsídios para a construção de um programa público de apoio à feira livre no Vale do São Francisco, MG. Organizações Rurais \& Agroindustriais, 13 (2), 186-200.

Skaerbaek, P. (2009). Public sector auditor identities in making efficiency auditable: the national audit office of denmark as independent auditor and modernizer. Accounting, Organizations and Society, 34, 971-987.

Thilmany, D., Bond, C. A., \& Bond, J. K. (2008). Going local: exploring consumer behavior and motivations for direct food purchases. American Journal of Agricultural Economics, 90 (5) 1303-1309.

Tonelli, D. F. (2011). O empreendedorismo de base tecnológica no complexo público de pesquisa em Minas Gerais: um olhar pelo calidoscópio da teoria Ator-Rede. 288 p. Tese (Doutorado em Administração) - Universidade Federal de Lavras.

Vergara, S. C. (2006). Métodos de pesquisa em administração. (2 ed.) São Paulo: Atlas, 2006.

Vollmer, H. (2007). How to do more with numbers: Elementary stakes, framing, keying, and the three-dimensional character of numerical signs. Accounting, Organizations and Society, 32, 577-600. 
Weatherell, C., Tregear, A., \& Allinson, J. (2003). In search of the concerned consumer: UK public perceptions of food, farming and buying local. Journal of Rural Studies, 19, 233-244.

ZEPEDA, L., LEVITEN-REID, C. (2004). Consumers' views on local food. Journal of Food Distribution Research, 35 (3), 1-6.

i Este trabalho foi apresentado XXXVII Encontro da ANPAD em 2013. 